\title{
Ion-Exchange Sorption and Preparative Chromatography of Biologically Active Molecules
}




\section{MACROMOLECULAR COMPOUNDS}

Series Editor: M. M. Koton, Institute of Macromolecular Compounds

Leningrad, USSR

ION-EXCHANGE SORPTION AND PREPARATIVE CHROMATOGRAPHY OF

BIOLOGICALLY ACTIVE MOLECULES

G. V. Samsonov 


\section{Ion-Exchange Sorption and Preparative Chromatography of Biologically Active Molecules}

\section{G. V. Samsonov}

Institute of Macromolecular Compounds

Leningrad, USSR

Translated from Russian by

R. N. Hainsworth

Translation Edited by

D. C. Sherrington

University of Strathclyde

Glasgow, Scotland 


\section{Library of Congress Cataloging in Publication Data}

Ion-exchange sorption and preparative chromatography of biologically active molecules.

(Macromolecular compounds)

Bibliography: p.

Includes index.

1. Ion exchange chromatography. 2. Biomolecules-Analysis. I. Samsonov, G. V. (Grigoriu Valentinovich) II. Series.

QP519.9.I54I66 1986

$543^{\prime} .0893$

86-19644

ISBN 978-1-4684-8910-1

ISBN 978-1-4684-8908-8 (eBook)

DOI $10.1007 / 978 \cdot 1-4684-8908-8$

This translation is published under an agreement with the Copyright Agency of the USSR (VAAP).

(C) 1986 Consultants Bureau, New York

Softcover reprint of the hardcover 1st edition 1986

A Division of Plenum Publishing Corporation

233 Spring Street, New York, N.Y. 10013

All rights reserved

No part of this book may be reproduced, stored in a retrieval system, or transmitted in any form or by any means, electronic, mechanical, photocopying, microfilming, recording, or otherwise, without written permission from the Publisher 


\section{Foreword}

This book deals with the physico-chemical principles underlying ionexchange sorption and chromatography. It does not cover in any detail the experimental and instrumental aspects of practical separations. The author has developed the subject starting from the synthesis and structure of the ion exchangers employed, through the thermodynamics of sorption selectivity and the equilibrium dynamics of ion sorption, to the kinetics and dynamics of non-equilibrium ion-exchange systems.

Throughout this treatment the additional factors arising from the exchange of complex organic ions, as opposed to simple mineral ones, have been interwoven. The author has stressed the application in the separation of organic ions with biological activity, many of which are synthesized in biotechnological processes, and in view of this he uses the expression "physico-chemical biotechnology." In practice, however, his in-depth treatment is applicable to any charged organic species with multifunctionality and/or high molecular weight, and is therefore by no means restricted to biologically active materials, and certainly not to those molecules from a biotechnological source. Bearing this in mind, the text has a much wider value than the title may convey.

Throughout his work the author has used the term "ionite" routinely as a very general expression for any ion exchanger. Most often these are typical ion-exchange resins based on crosslinked vinyl monomers, or polycondensation matrices. However, the term also encompasses inorganic-based ion-exchange materials, and occasionally linear polyelectrolytes used as models for the network systems. The derivatives "cationite" and "anionite" therefore have the same relationship as "cation exchanger" and "anion exchanger."

The text and accompanying figures and tables have been considerably streamlined by the use of abbreviations which have been gathered together for convenient reference. In this context the term "sulfocationite" has been coined to indicate a cation exchanger carrying a sulfonic acid group.

D. Sherrington 


\section{Preface}

The presentation of ideas adopted in this monograph is largely the result of many years of research and teaching at the Institute of Macromolecular Compounds of the USSR Academy of Sciences, Leningrad. I have given a course at the Chemical Pharmacology Institute, Leningrad, for 25 years called "The Theoretical Basis of Fine Physico-chemical Biotechnology" to final year students in the Faculty of Technology.

I consider myself fortunate that I can deal with both fundamental and applied problems at the same time when studying systems that include synthetic polymers (especially electrolytes) and organic and physiologically active substances (especially ions), and carry out scientific and applied research on the separation, purification, and fractionation of antibiotics, enzymes, hormones, amino acids, nucleotides, and many other groups of organic substances. Several groups of workers in different topic areas are united by their use of the general principles and concepts set out in this monograph, which covers ion exchange and preparative ionexchange chromatography using mixtures of organic and physiologically active substances.

The name of the course "The Theoretical Basis of Fine Physico-chemical Biotechnology," a name suggested over 25 years ago, is in keeping with the theoretical analysis of the scaling-up of processes for obtaining physiologically active substances under conditions in which they are chemically unreactive. This includes the processes of purification, isolation, and separation, as well as the methods of forming derivative structures to stabilize and modify the physiologically active substances to give them new properties. These may be to prolong the substances' activity or to direct them to specific targets in the organism. In this monograph we shall consider only some of these topics and shall analyze ion-exchange sorption and the preparative chromatography of physiologically active substances. Over the last. 25-30 years the area has been turned into a separate division of physical chemistry so that we can now use a small number of initial ideas to predict and establish the best materials, regimes, and methods for carrying out a preparation.

The last few years have also seen a tumultuous development of biology and biotechnology that has led to the appearance of a series of names for separate disciplines that can all be said to come within the science of universal chemical biology. Thus it can be maintained that areas such as bioorganic chemistry, biotechnology (the technology of directed biosynthesis), bioengineering, and technological enzymology all fall into this category. However, I believe it is right to keep to the term "fine chemical biotechnology" since the area of physico-chemical biotechnology described here lies within the definition given above. 
In the treatment of the concepts of fine physico-chemical biotechnology priority has been given to those that have appeared as a result of the work I or those under my supervision have carried out.

This book is a treatment of the theoretical basis of modern largescale separation, isolation, and purification of physiologically active substances using network polyelectrolytes and dynamic column regimes. Practical problems must be overcome on the basis of theoretical analyses of the physical chemistry of network polymer electrolytes, their thermodynamics and kinetics, and the dynamics of intermolecular interactions between them and organic ions. In this analysis, I draw mainly from the theoretical and experimental work of my colleagues and myself. The methods that have been developed have quite a general nature and can be applied to a variety of sorptive and chromatographic systems that lie on the fringes of the investigations covered here.

The first chapter justifies the idea that large-scale efficient methods for separating organic electrolytes can be created by combining the selectivity of the interactions of network polyelectrolytes and the sharp boundary regimes of dynamic frontal processes. That the separating power of frontal processes can be raised to that of contemporary eluant processes is demonstrated. This is done mainly by raising the quantity of substance to be separated to a value tens of thousands of times higher than that for a preparative eluant process in a comparably sized installation.

The second chapter considers the permeability of network polyelectrolytes. The morphology of net structures in the swollen state may be appraised only by using a number of investigative methods. The need for synthesizing heteronet structures (a class including macronets) that would be osmotically stable to changes in the ionic strength and $\mathrm{pH}$ of the environment, in order to improve the equilibrium and kinetic permeability of the polyelectrolyte and the reversibility of its sorption of complex ions, is emphasized. The thermodynamic and kinetic mobility of elements of the net structure is discussed. This effect was first demonstrated at the Institute of Macromolecular Compounds in Leningrad.

The third chapter is the largest and contains a thermodynamic analysis of intermolecular interactions in systems involving network polyelectrolytes and organic counter-ions. The interactions of weak and strong polyelectrolytes with weak and strong electrolytes in the surrounding solution are all considered from the same point of view. The concept of polyfunctional interactions between organic counter-ions and ionites is generalized and the cooperative, statistical, and concentration effects are considered. Quasi-ideal and non-ideal ionite systems are covered theoretically and experimentally. The large quantity of experimental evidence given in the chapter supports the validity of the principles derived.

In the fourth chapter I analyze the equilibrium dynamics of ion exchange based on concepts I have developed. Starting with column (dynamic) processes involving ions with the same charge, I pass on to more complicated systems that involve ions with different charges, weak electrolytes and weak polyelectrolytes, and those that involve two and three phases. Criteria are introduced which characterize the formation of sharp-boundary ion zones when the flow rate is low, and which can be used to predict the regimes needed for efficient preparative chromatography. Experimental data are provided that demonstrate the usefulness of the criteria.

The fifth chapter justifies new ways of intensifying separation processes for physiologically active substances that diffuse slowly in network polyelectrolyte beads. The theoretical analysis of the kinetics and dynamics of ion exchange is important when fast efficient methods are 
to be developed. What are needed are large-capacity sorbents that have good hydrodynamic properties without requiring expensive high-pressure equipment. The problem is overcome by using regimes that lie on the boundaries between quasi-equilibrium and regular processes, and by using new ionites for which the diffusion path for organic ions is short (e.g., surface-layer or bidispersed ionites). The theoretical analysis provided dimensionless numbers which can be used to describe the yield from quasi-equilibrium regimes. The new ionites and the theory have been used to realize the efficient large-scale liquid chromatography of physiologically active substances at high solution flow rates and short completion times. A series of examples at the end of the chapter illustrate separation and fractionation with these conditions.

I would like to thank my colleagues for their suggestions and comments. In preparing this manuscript I received the assistance of many collaborators and I would most like to acknowledge my debt to them all.

G. V. Samsonov 


\title{
Contents
}

\author{
CHAPTER ONE \\ INTRODUCTION
}

1.1 The Problems of Fine Physico-Chemical Biotechnology 1

1.2 Physico-Chemical Methods of Separating Mixtures 3

1.3 Preparative Selective Sorption and Chromatography 6

\section{CHAPTER TWO \\ IONITE PERMEABILITY AND POROSITY}

2.1 Types of Highly Permeable Network Polyelectrolytes 10

2.2 Methods for Studying the Permeability and Porosity
of Network Polyelectrolytes

2.3 The Structure and Properties of Very Permeable Network Polyelectrolytes

2.4 The Conformational State and Flexibility of the Structural Elements of Network Polyelectrolytes

CHAPTER THREE

ION-EXCHANGE EQUILIBRIUM, THERMODYNAMICS, AND SORPTION

SELECTIVITY OF ORGANIC AND PHYSIOLOGICALLY ACTIVE SUBSTANCES

3.1 Ionite Exchange Capacity 43

3.2 Equivalence of Ion Exchange $\quad 49$

3.3 Ion-Exchange Processes without the Sorption of
Physiologically Active Substances

3.4 Isotherms of Equivalent Ion Exchange 54

3.5 Ion Exchange on Ionites with Heterogeneous Active Centers 59

3.6 The Selectivity of Ion Exchange as a Function of the
Counter-Ion Mole Fraction in the Ionite

3.7 Sorption Selectivity of Ions as a Function of Electrolyte Concentration in the External Solution 67

3.8 Ion Exchange with Weak Electrolytes 70

3.9 Ion Exchange, Hydration, and Swelling 72

3.10 Selective Sorption of Organic Ions 74

3.11 Sorption of Organic Ions and Ionite Particle Size 84

3.12 Ion Exchange with Physiologically Active Substances 87

3.12.1 Antibiotics $\quad 87$

3.12.1a Antibiotics of the Tetracycline Group 88

3.12.1b Erythromycin and 0leandomycin 93

3.12.1c Penicillin and Novobiocin 96

3.12.1d Aminocyclitols (Streptomycin, Kanamycin, and Neomycin) 97

3.12.2 Amino Acids and Proteins 99

3.12.3 Nucleosides, Nucleotides, Alkaloids, Sulfonamides, and
Miscellaneous Physiologically Active Substances 
CHAPTER FOUR

EQUILIBRIUM DYNAMICS OF ION SORPTION AND

STANDARD QUASI-EQUILIBRIUM FRONTAL CHROMATOGRAPHY

4.1 Sharp Front Formation for the Exchange of Ions with the Same Valence

4.2 Formation of Sharp Fronts during the Exchange of Ions with Different Valences

4.3 Formation of Sharp Fronts when Two Liquids Are Involved

4.4 Sorption-Displacement for a Multicomponent Exchange in a Column

4.5 Standard Quasi-Equilibrium Frontal Chromatography on Ionites

KINETICS AND NON-EQUILIBRIUM ION-EXCHANGE DYNAMICS

5.1 The Diffusion of Organic Ions in Ionites

5.1.1 A Model of the Kinetics of Ion Exchange

5.1.2 Internal Diffusion Kinetics

5.1.3 Mixed Diffusion Kinetics (Linear Sorption Isotherm)

5.1.4 Sorption Kinetics in Ionites with Structural Heterogeneity

5.1.5 Experimental Investigations of the Diffusivities of Organic and Physiologically Active Ions in Ionite Beads

5.2 Theoretical Problems of Non-Equilibrium Dynamics of Sorption and Chromatography Involving Slowly Diffusing Organic Ions in Ionite Grains

5.3 Increasing the Efficiency of Low-Pressure Chromatography 


\section{Abbreviations}

The following are expansions of the abbreviations used in the text. Where there is not an obvious or meaningful English "translation," the original Russian abbreviation is transliterated. Abbreviations marked with an asterisk are trademark designations and so are transliterated. When an abbreviation is suffixed, the suffix indicates differences in crosslink ratio or synthesis conditions. Sulfo is a prefix indicating that a matrix is derivatized with a sulfonic acid group.

\section{Sulfocationites}

KU-2* Sulfonated copolymer of styrene and divinylbenzene

KRS* Sulfonated copolymer of styrene and $\mathrm{p}$-divinylbenzene

KU-6* Sulfoacenaphthene condensed with formaldehyde

KU-5* Sulfonaphthalene condensed with formaldehyde

KU-1* Sulfophenol condensed with formaldehyde

KFS Phenoxyethylsulfonic acid condensed with formaldehyde

KFSS $\quad \beta$-Phenoxyethanesulfosalicylic acid condensed with formaldehyde

KFSN $\quad \beta$-Phenoxyethanesulfonic acid condensed with $\beta$-naphthol and formaldehyde

KNS $\quad B$-(Naphthoxy)ethanesulfonic acid condensed with formaldehyde

KU-23* Macroporous sulfonated copolymer of styrene and divinylbenzene

SNK-E The sodium salt of 2-N-methacryloylamino-8-naphthol-6-sulfonic acid copolymerized with $\mathrm{N}, \mathrm{N}^{\prime}$-ethylenebismethacrylamide

SNK-H The above salt copolymerized with N,N'-hexamethylenebismethacrylamide

SNK-D The same with divinylbenzene

SNK-M The same with methylenebisacrylamide

SDV Sulfonated copolymer of styrene and divinylbenzene

SBS Sulfonated copolymer of styrene and butadiene

SKB Phenoxyethylsulfonic acid condensed with phenoxyacetic acid and formaldehyde

SFMAHMD Copolymer of 4-sulfophenylmethacrylamide and N,N'-hexamethylenebismethacrylamide

SK Surface-layer cationites which are impermeable glass spheres covered with a sorbing layer of a styrene/divinylbenzene copolymer

\section{Carboxylic Cationites}

CPA Phenoxyacetic acid condensed with formaldehyde

CPAC Phenoxyacetic acid condensed with chlorophenol and formaldehyde

KRFU Phenoxyacetic acid condensed with resorcinol and formaldehyde

KRFFU Phenoxyacetic acid condensed with resorcinol, phenol, and formaldehyde

$\mathrm{KB}-4 \mathrm{P}-2 * \quad$ Copolymer of methacrylic acid and divinylbenzene

$\mathrm{KB}-4 * \quad$ Copolymer of methacrylic acid and divinylbenzene 


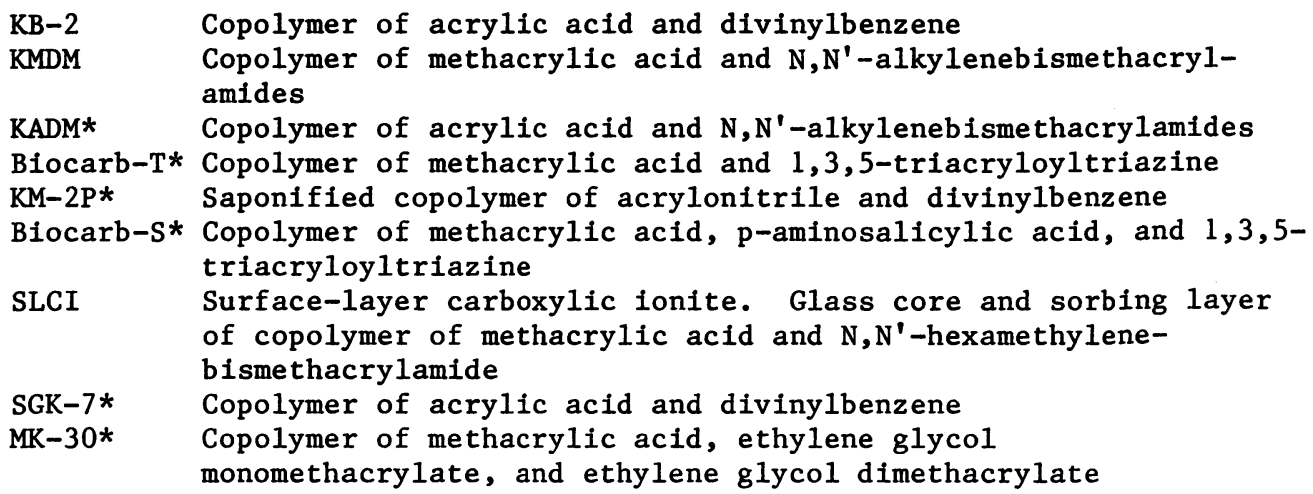

\section{Anionites}

$\begin{array}{ll}\text { ASD* } & \begin{array}{l}\text { Aminated chloromethylated copolymer of styrene and divinyl- } \\ \text { benzene } \\ \text { Aminated chloromethylated copolymer of styrene and butadiene } \\ \text { ASB* }\end{array} \\ \text { ARA* } & \begin{array}{l}\text { Aminated chloromethylated copolymer of styrene and p-divinyl- } \\ \text { benzene } \\ \text { Phenoxyethyltrimethylammonium salt condensed with formaldehyde } \\ \text { Phenoxyethyltrimethylammonium salt condensed with } \\ \text { FAKh }\end{array} \\ \text { AV-chlorophenol and formaldehyde } \\ \text { AV-17 } & \begin{array}{l}\text { Condensation product of pyridine and polyethylene- } \\ \text { polyamines withepichlorohydrin } \\ \text { Aminated chloromethylated copolymer of styrene and divinyl- } \\ \text { benzene }\end{array}\end{array}$

\section{Crosslinking Agents}

$\begin{array}{ll}\text { DVB } & \text { Divinylbenzene } \\ \text { DV } & \text { Diviny1 } \\ \text { B } & \text { Butadiene } \\ \text { HTA } & 1,3,5-T r i a c r y l o y l t r i a z i n e \\ \text { EDMA } & \mathrm{N}, \mathrm{N}^{\prime} \text {-Ethylenebismethacrylamide } \\ \text { HMDMA } & \mathrm{N}, \mathrm{N}^{\prime} \text {-Hexamethylenebismethacrylamide } \\ \text { DMDMA } & \mathrm{N}, \mathrm{N}^{\prime} \text {-Decamethylenebismethacrylamide }\end{array}$

\section{Miscellaneous Abbreviations}

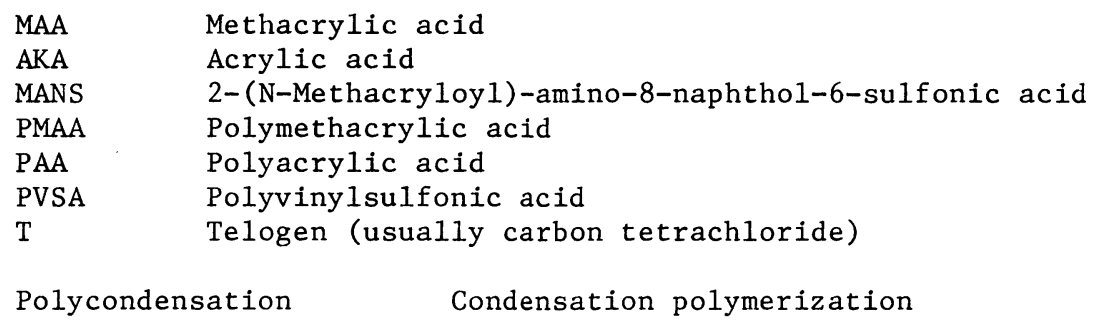

